\title{
Characterization of the Catalytic Properties of Recombinant Acetohydroxyacid Synthase from Tobacco
}

\author{
Joungmok Kim, Jung-Do Choi, ${ }^{\dagger}$ Bok-Hwan Kim,,${ }^{\ddagger}$ and Moon-Young Yoon ${ }^{\circ}$ \\ Department of Chemistry, Hanvang Lnversity, Seoul 133-791, Korea. "E-mail mvoonahanyang.ackr \\ ${ }^{\dagger}$ School of Life Sciences, Chungbuk Wational Lniversitw, Cheongit 361-763, Korea \\ ${ }^{\ddagger}$ Department of Health Science, Korea National Open Universitu, Seoul 110-791, Korea \\ Received October 30,2004
}

\begin{abstract}
The nature of the active site of Tobacco acetohydroxyacid synthase (AHAS) in the substrate- and cofactorbinding was studied by kinetics and fluorescence spectroscopy. The substrate saturation curve does not follow: Michaelis-Menten kinetics at different temperatures $\left(7.21\right.$ and $\left.37^{\circ} \mathrm{C}\right) . \mathrm{pH}(6.5 .7 .5$ and 8.5) and buffers (Tris$\mathrm{HCl}$ and MOPS). The concentration of one half of the maximum velocity ( $\left.\mathrm{S}_{0.5}\right)$ decreased in the following order: pynivate $>\mathrm{ThDP} \approx \mathrm{Mg}^{+2}>\mathrm{FAD}$. However. the catalytic efficiency $\left(\mathrm{K}_{\mathrm{cat}} / \mathrm{S}_{1,5}\right)$ inversely decreased in the following order: $\mathrm{FAD}>\mathrm{Mg}^{+2} \approx \mathrm{ThDP}>$ py nivate. indicating that the cofactors by in decreasing order: $\mathrm{FAD}$. $\mathrm{Mg}^{+}+\mathrm{ThDP}$. affect the catalysis of AHAS. The dissociation constant $\left(\mathrm{K}_{\mathrm{d}}\right)$ of the intrinsic tryptophan fluorescence decreased with the same tendency of the concentration of one half of the maximum velocity ( $\left.S_{1.5}\right)$ decreasing order. This data provides evidence that the substrate and cofactor binding natures of the active site. as well as its activation characteristics. resemble those of other ThDP-dependent enzz'mes.
\end{abstract}

Key Words : Acetolydroxyacid synthase, Kinetics. Fluorescence, Tobacco

\section{Introduction}

Acetohydroxyacid synthase (AHAS. EC 2.2.1.6 also referred to as acetolactate synthase) catalyzes the first common step in the metabolic pathway leading to biosynthesis of the branched-chain amino acids in plants and microorganisms. ${ }^{1.2}$ AHAS catalyzes the condensation of two molecules of pyruvate to form acetolactate in the biosynthesis of valine and leucine. or the condensation of pyrnvate and 2-ketobutyrate to form 2-aceto-2-hydroxybutyrate in the biosy'nthesis of isoleucine.

AHAS uses thiamine diphosphate (ThDP) as a coenzyme in the condensation reactions and also requires a divalent metal ion that anchors ThDP in the active site similar to other ThDP-dependent enzymes. AHAS has an essential requirement for $\mathrm{FAD}$. which is unexpected because the reaction involves no oxidation or reduction. The first two cofactors are typical for enzymes that catalyze the decarboxylation of 2-ketoacids as occurs in the first stage of the AHAS reaction. The requirement for FAD is not unprecedented and has also been described for glyoxylate carboligase. ${ }^{j}$ which is structurally related to AHAS as well as the unrelated enzyme. chorismate sy'nthase. ${ }^{4}$

The crystal structure of the catalytic subunit and AHAS enzyme from yeast was recently reported at $2.6 \AA$ resolution. This structure revealed the location of several active site features. including the position and the conformation of the cofactors ThDP. $\mathrm{Mg}^{2+}$ and FAD. The structure. in combination with molecular modeling. also suggested the geometry and location of the binding site for the imidazolinone herbicide imazapyr (2-(4-isopropy 1-4-methyl-5-oxo-2imidazolin-2-yl) nicotinic acid). Furthermore. molecular modeling analysis revealed the geometry and location of the binding site for the herbicide and provides for substrate access channel at the interface of the two monomeric subunits. Each monomer has three domains $(\alpha, \beta . \gamma)$. AHAS has two active sites that are on opposite faces of the molecule. We have studied the $\mathrm{pH}$ dependence of kinetic parameters in order to obtain information about the chemical mechanism in the active site ${ }^{7.22}$ Data was consistent with a mechanism in which the ThDP is ionized to the reactive ylide. The resulting carbanion attacks a pyruvate molecule stabilized by delocalization of electrons into the carboxyl probably with the assistance of enzyme residues in the vicinity of carboxyl. This yields the lactyl-ThDP intermediate via the transiently formed alcoholate anion. After decarboxylation, the enamine of hydroxyethyl-ThDP undergoes charge separation giving the $x$-carbanion that can now react with a second pyruvate to give the product complex. Finally, the product is released and ThDP is regenerated. Chemical modification studies. including site-directed mutagenesis studies have revealed that the $\operatorname{Trp} 490$ residue is essential for the catalytic function in tobacco AHAS. ${ }^{\S}$

Recently, we have determined from the quenching of intrinsic fluorescence the binding of ThDP to enzyme. The fluorescence quenching experiment was performed by titrating ThDP into a mixture of apoenzy'me in the presence of $100 \mathrm{mM}$ phosphate. $\mathrm{pH} 7.4 .2 \mathrm{mM} \mathrm{Mg}^{2+}$, and $20 \mu \mathrm{M}$ $\mathrm{FAD}$. The enzyme exhibits a fluorescence emission maximum at 340-345 $\mathrm{nm}$ upon excitation at $295 \mathrm{~nm}$. Using a continues assay. a time lag ( 400 second) was observed with tobacco AHAS enzyme at $40 \mathrm{mM}$ concentration of pynuate before a linear. steady state rate was attained. and showed a signoidal dependence of catalytic activity on pyruvate concentrations at $\mathrm{pH} 8.5^{10}$

In this paper. we report the characterization of AHAS 
from tobcico with respect to its kinetics and fluorescence towards the substrate (pyruvate) and activation by the three cofactors $\left(\mathrm{Mg}^{-\hat{2}}, \mathrm{ThDP}\right.$ and $\left.\mathrm{FAD}\right)$.

\section{Materials and Methods}

Chemicals. Pyruvic acid sodium salt, 4-morpholinepropanesulfonic acid (MOPS). tris(hydroxymethyl)aminomethane, flavin adenine dinucleotide (FAD), thiamin diphosphate (ThDP). $\alpha$-nlaphtol, creatine, glutathione. isopropyl$\beta$-D-thiogalactoside (IPTG), $\mathrm{NaCl}$, tritonX-100. glutathione and $\mathrm{MgCl}$ : were all purchased from Sigma Chemical Co. (St. Louis, USA). Epoxy-activated Sepharose 6B was obtained from Pharmacia Biotech (Uppsala. Sweden). All other chenicals were obtained from conmercial sources and were of the highest quality available.

Expression and Purification of Enzyme. Expression and purification of the recombinant acetohydroxyacid synthase was performed with modification as described by Chang et al. ${ }^{11}$ Briefly, E. coli $\mathrm{DH} 5 \alpha$ cells containing the expression vector pGEX-ALS were grown at $37^{\circ} \mathrm{C}$ in Luria-Bertani (LB) nediun containing $50 \mu \mathrm{g} / \mathrm{mL}$ ampicilin to an $\mathrm{OD}$ of $0.7-0.8$. Cells were induced by the addition of $1.0 \mathrm{mM}$ isopropyl-D-thiogalactoside (IPTG) and grown for an additional 4 hours at $30{ }^{\circ} \mathrm{C}$. Cells were harvested by centrifugation at $6000 \mathrm{rpm}$ for $15 \mathrm{~min}$. The cell pellet for the purification was resuspended in PBST buffer ( $150 \mathrm{mM}$ TrisHCl. pH 7.5, $1 \mathrm{mM}$ pyruvate, $10 \%(\mathrm{v} / \mathrm{v})$ ethy lene glycol, 10 $\mathrm{mM} \mathrm{MgCl}$ ) containing protease inhibitors $(2 \mu \mathrm{g} / \mathrm{mL}$ Leupeptin, $+\mu \mathrm{g} / \mathrm{mL}$ Aprotinin. $2 \mu \mathrm{g} / \mathrm{mL}$ Pepstatin A). The cell suspension was lysed by sonication at $4{ }^{\circ} \mathrm{C}$. The homogenate was centrifuged at $20,000 \mathrm{rpm}$ for $20 \mathrm{~min}$ and the supernatant was applied to a GSH-coupled Sepharose 6B column with PBST buffer. The GST-AHAS fusion protein was recovered from the column with an elution buffer ( 50 $\mathrm{mM}$ Tris- $\mathrm{HCl}, \mathrm{pH} 8.0,20 \mathrm{mM} \mathrm{GSH} .10 \%(\mathrm{v} / \mathrm{v})$ ethylene glycol). The isolated protein was identified by SDS-PAGE analy'sis and the protein concentration was determined by the method of Bradford.

Enzyme Assay. Enzyme activities of the purified AHAS were measured according to the method of Westerfeld ${ }^{12}$ with a modification as reported previously. ${ }^{13}$ The standard reaction mixture contained $100 \mathrm{mM}$ MOPS buffer $(\mathrm{pH} 7.5)$. $1 \mathrm{mM}$ ThDP. $10 \mathrm{mM} \mathrm{MgCl}, 20 \mu \mathrm{M} \mathrm{FAD} .75 \mathrm{mM}$ pyruvate. and the enzyme. Assays were initiated by the addition of AHAS at $37^{\circ} \mathrm{C}$ for $5 \mathrm{~min}$ and terminated by the addition of 6 $\mathrm{N} \mathrm{H}_{2} \mathrm{SO}_{4}$. The reaction product acetolydroxy acid was allowed to decarboxylate at $60^{\circ} \mathrm{C}$ for $15 \mathrm{~min}$. The acetoin formed by acidification was incubated and colorized with $0.5 \%$ creatine and $5 \% \%$-naphthol at $60{ }^{\circ} \mathrm{C}$ for $15 \mathrm{~min}$. All reactions were carried out in a $1-\mathrm{mL}$ cuvette with a 1 mumlight path-length. UV/vis absorbance spectra were recorded on a Cary $3 \mathrm{E} \mathrm{UV/vis} \mathrm{spectrophotometer.} \mathrm{The} \mathrm{absorbance} \mathrm{of}$ the reaction mixture was monitored at $525 \mathrm{~nm}$. The concentration of reactants was corrected for the concentration of the metal chelate complexes according to Dawson et $a f^{14}$ One unit $(\mathrm{U})$ of activity was defined as the amount required forming $1, \mu \mathrm{mol}$ of acetolydroxy acid per minute under the assay conditions described above. Specific activities of AHAS were expressed as units (U) per mg of protein.

Quenching of Intrinsic Protein Fluorescence. The substrate or the cofactors-dependent quenching of intrinsic protein fluorescence was monitored as a function of the substrate or the cofactors and the reduction in equilibrium fluorescence was monitored. Duplicate reactions were performed over the indicated concentration range in the presence of AHAS at $25^{\circ} \mathrm{C}$ in an initial volume of $500 \mu \mathrm{L}$ of $100 \mathrm{mM}$ MOPS, pH 7.5 and in the presence and absence of the other cofactors. Samples were excited at $295 \mathrm{~mm}$ (4-1m band pass) and were emission at $340 \mathrm{~nm}$ (4-nm band pass) in an SLM-Aminco 8100. The final concentration of AHAS used in the experiments was $4 \mu \mathrm{M}$. The quenching data was fitted to the following equation by using the program Enzfitter (a non-linear curve fitting program, BIOSOFT):

$$
\left(\Delta \mathrm{F} / \mathrm{F}_{\mathrm{c}} \times 100\right)=\left[\left(\Delta \mathrm{F}_{\max } / \mathrm{F}_{\mathrm{c}} \times 100\right)[\mathrm{Q}]\right] /\left(\mathrm{K}_{\mathrm{d}}+[\mathrm{Q}]\right)
$$

Where $\Delta \mathrm{F} / \mathrm{F}_{0} \times 100$ is the percent quenching (percent change in fluorescence relative to the initial value) following the addition of the quencher at a concentration [Q] and $\mathrm{K}_{d}$ is the dissociation constant.

Kinetic Data Collection. Reciprocal values of the steady state rate were plotted as a function of the reciprocal of the substrate concentrations. Data was analyzed according to the appropriate rate equations by using the FORTRAN programs of Cleland..$^{15}$ Individual saturation curves were fitted to Eq. (2).

$$
\mathrm{v}=\mathrm{VA} /(\mathrm{K}+\mathrm{A})
$$

In Eq. (2), $\mathrm{A}$ is the reactant concentration. $\mathrm{V}$ is the maximum velocity. and $\mathrm{K}$ is the Michaelis constant for the varied substrate.

\section{Results}

Steady-State Kinetic Parameter: After removal of the cofactors. AHAS showed little or no activity upon adding back any two of them (ThDP. $\left.\mathrm{Mg}^{2-}, \mathrm{FAD}\right)$. Full activity was restored only by the addition of a third cofactor with a hyperbolic dependence of the rate upon the cofactor concentration (data not shown). These data were analyzed to determine cofactor activation constants and were fitted to the Hill equation $\mathrm{v}_{\mathrm{o}} / \mathrm{E}_{\mathrm{o}}=\left(\mathrm{k}_{\mathrm{ca}} \mathrm{S}^{\mathrm{n}}\right) /\left[\left(\mathrm{S}_{1.5}\right)^{\mathrm{n}}+\mathrm{S}^{\mathrm{n}}\right]$, and the parameters were determined from a linear least-squares fit. The effect of pyruvate concentration on the rate of reaction was that the saturation curve does not follow the simple Michaelis-Menten kinetics in Figure 1. However, the positive cooperative saturation curve was shown fitting in Hill equation with $n=0.79$. Although the departure from a hyperbolic curve is rather subtle and might have been disregarded in a single experiment. it was observed consistently in multiple experiments.

In addition. substrate saturation curves obtained at different temperatures $\left(7.21\right.$ and $\left.37^{\circ} \mathrm{C}\right)$. pH values $(6.5 .7 .5$ 


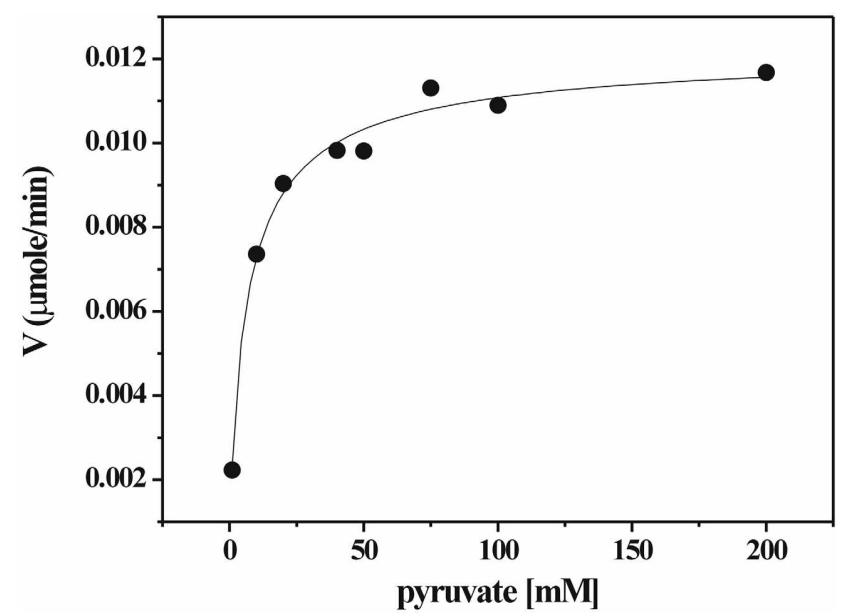

Figure 1. Saturation curve of the AHAS catalyzed reaction. The assays were conducted as described in Materials and Methods with the reaction mixture containing $100 \mathrm{mM}$ potassium phosphate buffer (pH 7.5), I $\mathrm{mM} 1 \mathrm{lhD}$, $10 \mathrm{mM} \mathrm{MoCl}, 20 \mu \mathrm{M}$ FAD, the enzyme and the indicated concentration of pyruvate. The points are experimental values and repeated at least three times. The curve is

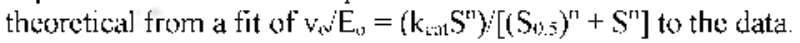

and 8.5 ) and buffers (Tris-HCl. HEPES and MOPS) yielded curves of a similar shape (dala nol shown). This kinclic anomaly is not an artifact arising from possible $\mathrm{pH}$ changes from the addition of high concentrations of substrate or colactors, as the $\mathrm{pH}$ of the assay bufler was unaltered by 100 m.M pyruvatc. Neither does it appear to be duc to a nonspecific effect of increasing ionic strength, since the inclusion of $100 \mathrm{mM} \mathrm{KCl}$ did not affect the lag phase and aclivity.

The effect of the each cofactor on AHAS was examined. The derived steady-state kinctic parameters at $\mathrm{pH} 7.5$ are presented in Table 1 . At this $\mathrm{pH}$, the concentration of onc half of the maximum velocity $\left(\mathrm{S}_{(, .5}\right)$ decreased in the following order: pyruvate $>\mathrm{ThDP}_{\mathrm{D}}=\mathrm{Mg}^{3}>\mathrm{FAD}$. However, the catalytic efficiency $\left(k_{\mathrm{cat}} / \mathrm{S}_{0,}\right)$ increased in the same order as the $S_{0.5}$ decreased.

Intrinsic Fluorescence Measurements. The intrinsic fluorescence emission specira for pyruvate in the AHAS encyme are shown in Figure 2. AHAS has a fluorescence emission maximum at $340 \mathrm{~nm}$ upon excitation at $295 \mathrm{~nm}$. The data is described by eq. (1), as shown by the lines in Figure 3 ; the values of the various kinetic parameters are summarized in Table 2. Titration of AHAS with pyлuvate resulted in an $89 \%$ reduction of the initial Trp lluorescence. The dissociation constant $\left(\mathrm{K}_{\mathrm{b}}\right)$ of pyruvate was $24.8 \pm 2.76$ $\mathrm{mM}$ in the absence of cofactors, however, it was $18.38 \pm$

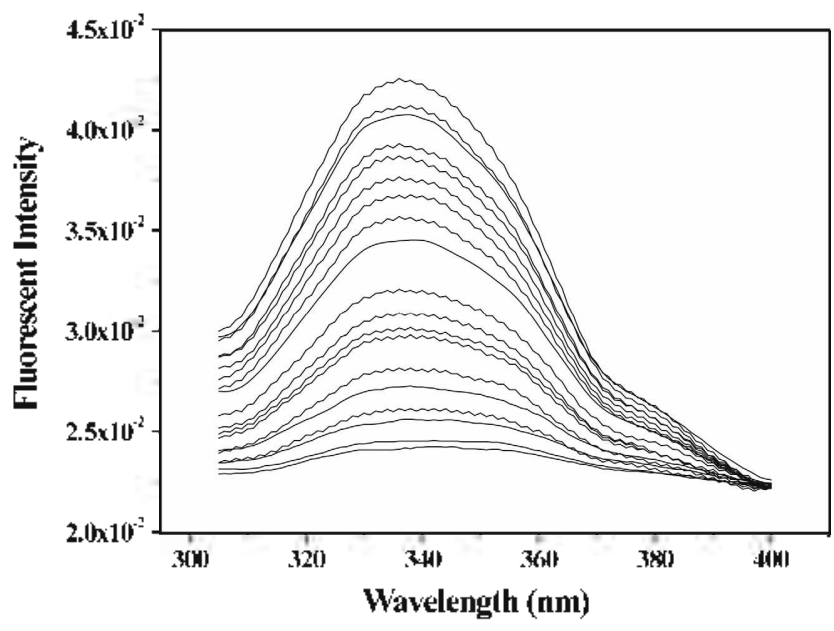

Figure 2. Fluorescence emission spectra of the pyruvate saturation in the $\mathrm{AH} A \mathrm{~S}$ enzyme. The fluorescence spectra were recorded at $25^{\circ} \mathrm{C}$ in $100 \mathrm{mM}$ MOPS bulfer, pH 7.5. The emission curves are shown for the pyruvate concentration range of $0,5,7,10,12,14$. $16,18,20,30,40,50,60,75,100,120,150,200 \mathrm{mM}$.

$1.56 \mathrm{mM}$ in the presence of $0.3 \mathrm{m.M}$ ThDP and $1 \mathrm{mM} \mathrm{Mg}$, indicating that the cofactors ( $\mathrm{ThDP}$ and $\mathrm{Mg}^{2}$ ) do not affect pyruvate binding affinity.

The $K_{d}$ of ThDP was $0.52 \pm 0.17 \mathrm{mM}$ in the absence of cofactors, however, $0.22 \pm 0.03 \mathrm{mM}$ in the presence of ? $\mathrm{mM} \mathrm{Mg}$, and $0.40=0.08 \mathrm{mM}$ in the presence of $10 \mathrm{mM}$ pyruvate and $2 \mathrm{mM} \mathrm{Mg}$. The affinity $(0.52 \mathrm{mM})$ for ThDP in the absence of any cofactor was similar $(0.40 \mathrm{mM})$ to the presence of $10 \mathrm{mM}$ pyluvate and $2 \mathrm{mM} \mathrm{Mg}{ }^{2}$.

The $K_{d}$ of $\mathrm{Mg}^{2}$ was $0.074 \pm 0.008 \mathrm{mM}$ in the absence of cofactors and $0.126 \pm 0.04 \mathrm{mM}$ in the presence of $0.3 \mathrm{mM}$ ThDP. The $\mathrm{K}_{\mathrm{d}}$ of $\mathrm{Mg}^{2}$ was not clanged in the presence or abscnce of ThDP, suggesting that $\mathrm{Mg}^{2}$ binding to the active sile was not affected by ThDP. Magnesium ion hold the ThDP in place by coordinating to two of the phosphate oxygen atoms and two amino acid side chains (vide infrot. The $K_{d}$ of $\mathrm{FAD}$ was $2 . \mathrm{I}=0.3 \mu \mathrm{M}$ in the absence of cofactors, however, and $2.8 \pm 0.3 \mu \mathrm{M}$ in the presence of 0.3 $\mathrm{mM} \mathrm{ThDP}$ and $1 \mathrm{mM} \mathrm{Mg}$, indicating that ThDP and $\mathrm{Mg}^{2}$ do not effect the binding of FAD to the enryme.

\section{Discussion}

AHAS has two active sites, which are on opposite faces of the molecule. Each active site is bordered by amino acid residucs from both monomers. AHAS, in common wilh several other enzymes that catalyze the decarboxylation of 2-ketoacids, uses thiamine diphosplate (ThDP) as a cofactor

Table 1. The Steady State Kinetic Parameters of AHAS at pH 7.5 (100 mM MOPS, $25^{\circ} \mathrm{C}$ )

\begin{tabular}{|c|c|c|c|c|}
\hline & Pysuvate & ThDP & $\mathrm{Mgg}^{2}$ & $\mathrm{FAD}$ \\
\hline$K_{\text {: }: 11}\left(s^{-1}\right)$ & $16.10+0.83$ & $12.35+0.92$ & $10.90+1.02$ & $9.72-0.45$ \\
\hline$S_{115}(\mathrm{mM})$ & $6.53 \pm 0.8$ & $0.78 \pm 0.26$ & $0.56 \pm 0.20$ & $1.30 \pm 0.30^{\mathrm{w}}$ \\
\hline
\end{tabular}

"values scale is $H \mathrm{M}$. value scale is $\mathrm{M}$ 's ' 

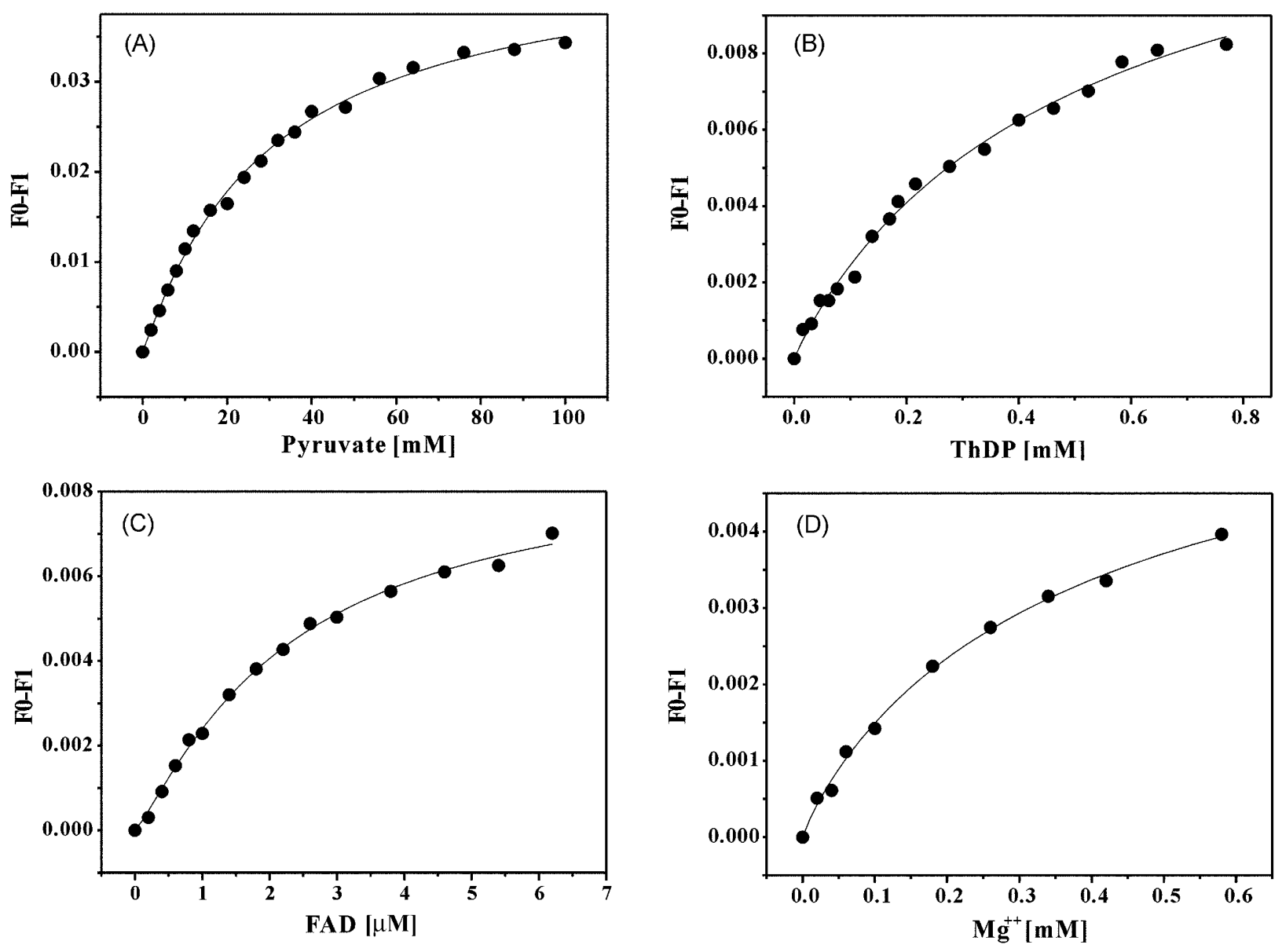

Figure 3. Substrate and cofactor saturation plots for pynuate (A), ThDP (B), FAD (C), and $\mathrm{Mg}^{2}$ (I) with cofactor (substrate) concentration shown on a molar seale. texperiments were carried out in 100 mM MOPS buffer, pH 7.5 The eurves shown represent the fit of the data to the Hill equation.

Table 2. Parameters of quenching the intrinsic fluorescence of NHAS upon addition of cofactor"

\begin{tabular}{lccc}
\hline & $\begin{array}{c}\text { apparent Kd } \\
(\mathrm{mM})\end{array}$ & $\begin{array}{c}\text { maximal quenching } \\
(\%)\end{array}$ & $n$ \\
\hline pynuvate & $24.80 \pm 2.76^{\prime \prime}$ & $89 \pm 4.32$ & 1.11 \\
& $18.38 \pm 1.56^{\circ}$ & $74 \pm 1.25$ & 0.78 \\
ThDP & $0.52 \pm 0.17^{\prime \prime}$ & $71 \pm 4.12$ & 0.95 \\
& $0.22 \pm 0.03^{\circ}$ & $69 \pm 2.2$ & 1.44 \\
& $0.40 \pm 0.08^{\circ}$ & $68 \pm 2.1$ & 1.03 \\
$\mathrm{Mgg}^{2}$ & $0.074 \pm 0.008^{\prime \prime}$ & $8.02 \pm 0.91$ & 2.55 \\
& $0.126 \pm 0.04$ & $5.74 \pm 0.54$ & 1.67 \\
FAD & $0.0021 \pm 0.0003^{\prime \prime}$ & $38.28 \pm 2.21$ & 1.28 \\
& $0.0028 \pm 0.0003^{\prime}$ & $33.13 \pm 0.14$ & 1.19 \\
\hline
\end{tabular}

"Values oblained without any cofactors. "Values obtained with $0.3 \mathrm{mM}$ ThDP and I mM Mg. "Values obtained with $2 \mathrm{mMM}$ M. "Values obtained with $10 \mathrm{mM}$ pyruvate and $2 \mathrm{mM} \mathrm{Me}$. "Values obtained with $0.3 \mathrm{mM}$ ThDP. "Values oblained with $0.3 \mathrm{mM}$ ThDP and I mM Mg. "All assas were pertormed at $25{ }^{\circ} \mathrm{C}$ in $100 \mathrm{mM}$ MOPS buffer. $\mathrm{pH} 7.5$. Firors are the S.D. of at least three independent experiments

and requires a divalent metal ion (usually $\mathrm{Mg}^{2}$ ) that anchors ThDP in the active site. AHAS also has an essential requirement for $\mathrm{FAD}$. Although AHAS requires the three cofactors for the catalytic reaction. little is known about the catalytic nature. It was necessary to elucidate the catalytic characteristic in the active site of the enyme in more detail.

The concentration of one half of the maximum velocity $\left(\mathrm{S}_{1,5}\right)$ at $\mathrm{pH} 7.5$ decreased in the following order: pyruvate $>$ ThDP $\approx=\mathrm{Mg}^{2}>$ FAD. However, the calalylic efficiency $\left(k_{\text {cal }} / S_{(1,5}\right)$ increased in the same order as the $S_{0,5}$ decreased. These results suggested that the cofactors affect substrate (pyruvate) binding aflinity, for cxample, $\mathrm{FAD}$ binding induced the catalytic efficiency $\left(\mathrm{K}_{\mathrm{c} \text { at }} / \mathrm{S}_{0.5}\right) 3000$-fold. This belavior is consistent with the model that we have proposed previously, whereby FAD bound to a crevice of the first monomer contacts the second monomer, suggesting the FAD molecule plays a crucial role in the stabilization of the dimer interface. Monomeric FAD displays litte activity. Both of ThDP and $\mathrm{Mg}^{2}$ binding induced the catalytic efficiency approximately 8 -fold. ThDP is located centrally in the active sile spanning the two monomers. The diphospliate porlion of ThDP interacts with $\mathrm{Mg}^{2}$ and with amino acid residues from the $\gamma$-domain. As in all other ThDP-dependent crrymes, the role of the metal ion is the same; it acts as an anchor to hold the ThDP in place by coordinating with two of the phosphate oxygen atoms and two amino acid side chains. $^{2}$ Therefore, it makes sense that the addition of $\mathrm{Mg}^{2}$ to AHAS showed increased catalytic efficiency ( 8 -fold) the 
ThDP addition of to AHAS.

We have shown previously that the substrate saturation curve did not follow Michaelis-Menten kinetics. ${ }^{10}$ a general feature of plant AHASs was observed. ${ }^{16,17.18}$ Using the continuous assay. a large lag phase before full activity of the enzyme was attained. ${ }^{10}$ This lag phase could not be eliminated by the preincubation of the enzyme under assay conditions in the absence of substrate. The data exhibited positive co-operativity. which we have interpreted as arising from interactions between the subunits of this homodimeric enzyme. Using the discontinuous assay. a large lag phase was observed before full activity of the enzyme was attained. The cofactor saturation curves showed negatively co-operative kinetics (data not shown). The difference in the results of co-operativity may be attributed by the assay method between a continous assay and a discontinous assay. indicating that an artifact effect by a discontinous assay and/ or conformational changes may possibly account for the transient kinetics. It has also been reported that for barley, ${ }^{19}$ Arabidopis thatiana ${ }^{301}$ and Serratia marescens ${ }^{21}$ AHAS. reactivation by cofactors was time-dependent. We have also observed lags of a few minutes before attainment of full activity after the addition of the cofactor.

The quenching of tryptophan fluorescence provides a direct tool for the determination of the dissociation constant of a protein-ligand complex. However. the sensitivity of the method depends on the number and location of the fluorophores. Tobaco AHAS exhibited intrinsic fluorescence characteristics in the presence of tryptophan residues, very likely buried in the protein as revealed by a low fluorescence enission maximum $(340-345 \mathrm{~nm})$ upon excitation at 295 Int.

The $\mathrm{K}_{d}$ of AHAS exhibited sumilar behavior $(24.8 \mathrm{mM}$ and $18.4 \mathrm{mM}$ ) when titrated with pyruvate in the presence and absence of the cofactors (ThDP and $\mathrm{Mg}^{-2}$ ). However. the $\mathrm{K}_{\mathrm{m}}$ of pyruvate was $6.53 \mathrm{mM}$. The off-rate $\left(\mathrm{k}_{-1}\right)$ is approximately 20 -fold higher than the on-rate $\left(\mathrm{k}_{1}\right)$, indicating that pynuate is not sticky on the enzyme. The termini of the mobile loop in the C-terminal region of AHAS are near the active site and it may be repositioned during catalysis. The mobile loop is confined by packing forces when ThDP and $\mathrm{Mg}^{-\hat{\imath}}$ are combined in the active site. ${ }^{6}$ No matter what circumstance the mobile loop may be confined as the pyruxate close to the active site.

The affinity for ThDP was increased 2-fold $(0.4 \mathrm{mM}$ to 0.2 $\mathrm{mM}$ ) in the presence of only $\mathrm{Mg}^{+2}$. suggesting that ThDP with $\mathrm{Mg}^{+2}$ induces a conformational change leading to an increasing binding. These results agree with that $\mathrm{Mg}^{\hat{*}}$ is required for optimum binding and for catalysis of ThDP in the active site (vide ante) ${ }^{6}$ i.e. ThDP is located centrally in the active site spanning the two monomers and the diphosphate portion of ThDP interacts with $\mathrm{Mg}^{+2}$ and with anino acid residues from the $\gamma$-donain.

FAD is bound in an extended conformation and is located in a crevice bounded by all three domain. ${ }^{6}$ The high affunity ( $\mu \mathrm{M}$ range rather than $\mathrm{mM}$ range of $\mathrm{K}_{\mathrm{d}}$ ) of $\mathrm{FAD}$ is due to numerous hydrogen bonds and van der Waals interactions between FAD and the enzyme based on crystallographic analy sis. Pang et ol. ${ }^{6}$ have proposed that the FAD molecule does not appear to play a direct role in stabilization of the dimer interface since there is the only one hydrophobic contact ( $C 8$ methyl group of the flavin ring and Phe201 from the second monomer in yeast) to the second monomer. However. they have proposed that FAD could participate directly in catalysis. Our results have revealed that there is no affinity difference whether the other cofactors (ThDP and $\mathrm{Mg}^{+3}$ ) are present or not, indicating that FAD binding does not play any active role in catalysis. It has been proposed that $F A D$ is a vestigial renunant reflecting the evolution of AHAS from a POX-like ancestor. ${ }^{16}$ It appears that FAD in AHAS is required solely for structural reasons. maintaining the enzyme active site in the required geometry for catalysis to occur.

Acknowledgements. This work was supported in part by research grants from Hanyang University (2003).

\section{References}

1. Umbarger. H. Amm. Rev Biochent 1978. 47. 533-606

2. Duggleby. R.: Pang. S. J. Biochent. Mol. Biol 2000. 33. 1-36.

3. Chang. Y.: Wang. A.: Cronan. T. J. Biol Chent 1993. 268. $3911-$ 3919.

4. Macheroux, P.: Schonbrunn, E.: Svergun, D.: Volkov, D.: Koch. M.: Bomemann. S: Thomeley. R. Biochem. J. 1998, 335. 319327.

5. Pang. S.: Guddat. L.: Duggleby. R. Acta Cristallog. 2001. Sect. D 57. 1321-1323.

6. Pang. S.: Duggleby. R: Guddat, L. J. Hol. Biol. 2002. 317. 249262.

7. Yoon. M. Y.: Hwang. J. H.: Choi, M. K; Back. D. K.: Kim, J.; Kim. Y. T.: Choi. J. D. FEBS Letters 2003. 555. 185-191.

8. Chong. C. K.: Shin. H. J.: Chang. S. I.: Choi. T. D. Biochent Biophus Res. Conmum. 1999. 259. 136-140.

9. Kim. J.: Baek, D. K.: Choi. J. D.: Kim. Y. T: Yoon, M. Y. Biochem. J. 2004, 383. 1-10.

10. Hwang. J.: Kim. J.: Kim. Y. T.; Choi. J. D; Yoon, M. Y. Bull. Korean Chem. Soc. 2003. 2t. 1856-1858.

11. Chang. S. I.: Kang. M. K.: Choi. J. D.: Namgoong. S. K. Biochent. Biophs. Res. Conmum. 1997. 234. 549-553.

12. Westerfeld. W. W. J. Biol. Chem. 1943. 161. 495-502.

13. Lee. Y. T.: Chang, A. K; Duggleby, R. G. FEBS Lett. 1999, 452. 341-345.

14. Dawsot1. R. M. C.: Elliott. D. C.: Elliott. N. H.: Tohtes. K. M. Data for Biochemical Research. $2^{\text {nd }}$ ed: Osford University: Londont. 1979: p 423

15. Cleland. W. W. Methods Enzwnol. 1979, 63, 103-147.

16. Pang. S. S.; Duggleby: R. G.: Guddat. L. W. J. Mol. Biol. 2002. $317.249-262$.

17. Schloss. T. V.: Van Dyk. D. E.: Vasta. J. F.: Kutt1y. R. M Biochentisny 1985. 2H. 4952-4959.

18. Chang. A. K.: Duggleby. R. G. Biochem. J. 1998. 333. 767-777.

19. Miflin, B. J. Arch Biochem. Biophys. 1971. 146. $542-550$.

20. Chang. A. K.: Duggleby. R. G. Biochem. J. 1997, 327. 161-169.

21. Yang. J. H.; Kim. S. S. Biochim. Biophys. Acta 1993, 1157. 178 184.

22. Choi. T. D.: Kim. B. H.: Yoon. M. Y. Bull. Korean Chent. Soc 2003. 24. 627-632. 